\title{
Erratum to: Children's Attitudes About an Overweight or Non-overweight Weight Victim
}

\author{
Laura Nabors • Myra Thomas • Lisa Vaughn • \\ Ryan Adams • Joe Amaral • Brian T. Olsen • \\ Christopher F. Bolling
}

Published online: 1 October 2010

(C) Springer Science+Business Media, LLC 2010

\section{Erratum to: J Dev Phys Disabil \\ DOI 10.1007/s10882-010-9203-3}

In the original version of this article, one of the authors was not included. The list of six authors on the original article should have been seven, counting Dr. Bolling. His complete affiliation is given below.

The online version of the original article can be found at http://dx.doi.org/10.1007/s10882-010-9203-3.

L. Nabors $(\bowtie) \cdot$ M. Thomas $\cdot$ J. Amaral $\cdot$ B. T. Olsen

Department of Psychology,

University of Cincinnati, Mail Location 376, Cincinnati, OH 45221-0376, USA

e-mail: naborsla@ucmail.uc.edu

L. Vaughn

Division of Emergency Medicine, Community Pediatrics,

Cincinnati Children's Hospital Medical Center, Cincinnati, OH, USA

R. Adams

Division of Developmental and Behavioral Pediatrics,

Cincinnati Children's Hospital Medical Center, Cincinnati, OH, USA

C. F. Bolling

Department of Pediatrics,

University of Cincinnati College of Medicine, Cincinnati, OH, USA

e-mail: bollingcf@gmail.com

e-mail: christopher.bolling@cchmc.org 